\title{
475319 - OXYTOCIN PRE-TREATMENT DECREASES OXYTOCIN-INDUCED MYOMETRIAL CONTRACTIONS IN PREGNANT RATS IN A DOSE BUT NOT TIME-DEPENDENT MANNER
}

\author{
Mrinalini Balki, MBBS, MD ${ }^{1}$, Joyce Magalhaes, MD $^{1}$, Robert Parkes, PhD $^{2}$, John \\ Kingdom, $\mathrm{MD}^{2}$, Yonge Li, $\mathrm{MD}^{1}$, Jose Carvalho, $\mathrm{MD}, \mathrm{PhD}^{1}$ \\ 1. Anesthesia, Mount Sinai Hospital, Toronto, ON, Canada \\ 2. Obstetrics and Gynecology, Mount Sinai Hospital, Toronto, ON, Canada
}

Introduction: Recent bio-molecular studies have shown that continuous exposure of human myometrial cells to oxytocin can result in a significant loss in their capacity to respond to oxytocin, due to desensitization of the oxytocin receptors.1, 2 However, it is unclear if this phenomenon results in a reduction of the contractile activity of the uterine muscle in humans or animals. The objective of our study was to investigate the in-vitro response of the uterine muscle to oxytocin in pregnant rats, after pre-exposure to different concentrations of oxytocin for variable durations.

Methods: After approval by the Animal Care Committee at Mount Sinai Hospital, the study was conducted in 30 pregnant Wistar rats at 19-21 days of gestation. Four longitudinal myometrial strips ( $2 \times 2 \times 10 \mathrm{~mm}$ each) were isolated from each animal, and allowed to equilibrate in $10 \mathrm{ml}$ organ bath chambers containing physiological salt solution (PSS) at $1 \mathrm{~g}$ tension. Two strips were then exposed to either 10-10 M or 10-8 M oxytocin (experimental groups), and the other two were kept in PSS (control groups), for 1h. All muscle strips were then subjected to a dose-response study with oxytocin (10-10 to10-5 M). Similar experiments were done after the exposure of separate myometrial strips to oxytocin/ PSS for $4 \mathrm{~h}$. The contraction data, in the form of amplitude, frequency and integrated area under the contraction curve (AUC), were recorded for each sample and analyzed using mixed linear modeling.

Results: The summary of the results is presented in Table 1. The AUC, frequency and amplitude of the myometrial contractions after pre-exposure to $10-8 \mathrm{M}$ oxytocin were smaller as compared to the control groups ( $<<0.0001, \mathrm{p}=0.0002, \mathrm{p}<0.0001$ respectively). However, the pre-treatment with 10-10M oxytocin had no effect on the contractile response as compared to the control groups. There was no difference between preexposure to oxytocin for either the $1 \mathrm{~h}$ or $4 \mathrm{~h}$ period.

Discussion: The inhibition of the contractile response of pregnant rat myometrium seen after pre-exposure to oxytocin is dependent on the concentration of oxytocin to which the preparation has been exposed, and not on the duration of its exposure. Similar studies are warranted in human myometrium, and should have significant clinical implications in the management of oxytocin-induced or augmented labors, and also in the treatment of postpartum hemorrhage.

References: 1. Hum Reprod Update 1998; 4: 625-33. 2. Am J Obstet Gynecol 2003; 188: 497-502.

Table 1. Estimated means for each outcome by pretreatment regimen, with estimated differences (with p-values) between doses or period 


\begin{tabular}{|c|c|c|c|c|}
\hline Pretreatment Regimen & $\mathrm{N}$ & AUC $(\mathrm{gm} * \mathrm{sec})$ & $\begin{array}{c}\text { Frequency (per 10 } \\
\text { min) }\end{array}$ & Amplitude (gm) \\
\hline$-10 \mathrm{M}$ for 1 h & 8 & 1374.4 & 8.45 & 2.265 \\
\hline$-10 \mathrm{M}$ for 4 h & 8 & 1670.3 & 7.19 & 2.735 \\
\hline$-8 \mathrm{M}$ for 1 h & 6 & 848.4 & 5.13 & 1.394 \\
\hline$-8 \mathrm{M}$ for 4 h & 8 & 1003.7 & 6.49 & 1.655 \\
\hline Control for 1 h & 14 & 1366.8 & 8.26 & 3.269 \\
\hline $\begin{array}{c}\text { Control for 4 h } \\
\text { Effect estimates }(\text { with } \\
\text { p-values })\end{array}$ & 16 & 1842.5 & 8.94 & 3.031 \\
\hline$-10 \mathrm{M}$ vs control & & $-4.52 \%(\mathrm{p}=0.55)$ & $-0.78(\mathrm{p}=0.28)$ & $-5.11 \%(\mathrm{p}=0.50)$ \\
\hline$-8 \mathrm{M}$ vs control & & $-41.84 \%$ & $-2.79(\mathrm{p}=0.0002)$ & $-42.08 \%$ \\
$(\mathrm{p}<.0001)$ & $+0.0001)$ \\
\hline 4 h vs 1h & & $+4.33 \%(\mathrm{p}=0.06)$ & $+0.26(\mathrm{p}=0.80)$ & $+24.20 \%(\mathrm{p}=0.07)$ \\
\hline
\end{tabular}

